\title{
Prática do Direito Sistêmico: Importância no contexto judicial brasileiro e influência
}

\section{na Justiça Restaurativa}

Systemic Law Practice: Importance in the Brazilian judicial context and influence on Restorative

Justice

Práctica del Derecho Sistémico: Importancia en el contexto judicial brasileño e influencia en la Justicia Restaurativa

\section{Resumo}

Este artigo é resultado de uma pesquisa bibliográfica com o objetivo de apresentar um breve histórico da prática do Direito Sistêmico no Brasil enquanto ferramenta na aplicação de uma dinâmica de Justiça Restaurativa, evidenciando sua importância no contexto jurídico brasileiro atual. O estudo é parte de uma pesquisa de mestrado em andamento que investiga a atuação de 7 (sete) magistrados no Brasil acerca da prática do Direito Sistêmico. Apresenta a importância dessa prática, haja vista sua criaçãoladaptação por um juiz brasileiro, Dr. Sami Storch a partir das Constelações Familiares, procedimento terapêutico criado por Bert Hellinger. Ao longo da reflexão teórica, se propõe pensar no contraste entre Justiça Restaurativa e Justiça Retributiva, trazendo as ferramentas que podem ser utilizadas para o exercício da primeira, quais sejam: mediações, círculos da paz ou restaurativos, práticas participativas, direito sistêmico com o protagonismo deste último. Apoiado na Declaração da ONU - Organização das Nações Unidas - ONU - o texto mostra a regulamentação das práticas de Justiça Restaurativa no mundo, por meio de três resoluções nos anos de 1999, 2000 e 2002, cujos documentos servem de referência para o trabalho da Justiça Restaurativa nos países signatários do órgão. No Brasil, a Justiça Restaurativa tem seu marco legal com a Carta de Brasília, a qual manteve as características contidas na Resolução 2002/12 da ONU. Conclui-se que os princípios do Direito Sistêmico, portanto, constituem-se como prática da justiça restaurativa, sendo estas duas abordagens complementares. Ainda estamos longe de uma implantação generalizada, pois abordar o Direito Sistêmico compete aplicar a prática da ciência jurídica frente a este viés terapêutico, onde se vislumbra utilizá-lo para tratar questões geradoras de conflitos, principalmente durante a formação do bacharel em Direito.

Palavras-chave: Constelações familiares; Práticas colaborativas; Educação para a paz.

\begin{abstract}
This article is the result of a bibliographical research with the objective of presenting a brief history of the practice of Systemic Law in Brazil as a tool in the application of Restorative Justice dynamics, highlighting its importance in the current Brazilian legal context. The study is part of an ongoing master's research that investigates the performance of 7 (seven) magistrates in Brazil about the practice of Systemic Law. It presents the importance of this practice, considering its creation and adaptation by a Brazilian judge, Dr. Sami Storch, based on Family Constellations, a therapeutic procedure created by Bert Hellinger. Along the theoretical reflection, it is proposed to think about the contrast between Restorative Justice and Retributive Justice, bringing the tools that can be used for the exercise of the former, which are: mediations, peace or restorative circles, participative practices, systemic law with the protagonism of the latter. Supported by the UN Declaration - United Nations Organization - the text shows the regulation of Restorative Justice practices in the world, through three resolutions in the years 1999, 2000 and 2002, whose documents serve as reference for the Restorative Justice work in the signatory countries of the organ. In Brazil, Restorative Justice has its legal mark with the Charter of Brasília, which kept the characteristics contained in the UN Resolution 2002/12. We conclude that
\end{abstract}


the principles of Systemic Law, therefore, constitute the practice of restorative justice, and these two approaches are complementary. We are still far from a generalized implementation, since to approach Systemic Law is to apply the practice of legal science in face of this therapeutic bias, where it is glimpsed to use it to treat issues that generate conflicts, especially during the formation of the bachelor in Law.

Keywords: Family constellations; Collaborative practices; Education for peace.

\section{Resumen}

Este artículo es el resultado de una investigación bibliográfica con el objetivo de presentar una breve historia de la práctica del Derecho Sistémico en Brasil como herramienta en la aplicación de la dinámica de la Justicia Restaurativa, destacando su importancia en el contexto jurídico brasileño actual. El estudio forma parte de una investigación de maestría en curso que investiga el desempeño de 7 (siete) magistrados en Brasil sobre la práctica del Derecho Sistémico. Presenta la importancia de esta práctica, considerando su creación y adaptación por parte de un juez brasileño, el Dr. Sami Storch de las Constelaciones Familiares, procedimiento terapéutico creado por Bert Hellinger. A lo largo de la reflexión teórica, se propone pensar en el contraste entre la Justicia Restaurativa y la Justicia Retributiva, acercando las herramientas que se pueden utilizar para el ejercicio de la primera, que son: las mediaciones, los círculos de paz o restaurativos, las prácticas participativas, el derecho sistémico con el protagonismo de la segunda. Basado en la Declaración de la ONU - Organización de las Naciones Unidas - el texto muestra la regulación de las prácticas de Justicia Restaurativa en el mundo, a través de tres resoluciones en los años 1999, 2000 y 2002, cuyos documentos sirven de referencia para el trabajo de Justicia Restaurativa en los países firmantes del órgano. En Brasil, la Justicia Restaurativa tiene su marca legal con la Carta de Brasilia, que mantuvo las características contenidas en la Resolución 2002/12 de la ONU. Se concluye que los principios del Derecho Sistémico, por lo tanto, constituyen la práctica de la justicia restaurativa, siendo estos dos enfoques complementarios. Todavía estamos lejos de una implantación generalizada, porque abordar el Derecho Sistémico es aplicar la práctica de la ciencia jurídica frente a este sesgo terapéutico, donde es posible utilizarlo para tratar temas que generan conflictos, especialmente durante la formación del bachiller en Derecho.

Palabras clave: Constelaciones familiares; Prácticas colaborativas; Educación para la paz.

\section{Introdução}

O Direito, como ciência, se conecta diretamente com as demais ciências sociais, como a própria sociologia, a antropologia e a psicologia. Embora o código judicial exista justamente para solucionar questões em que a Lei em seu sentido amplo e irrestrito deve ser cumprida, não obstante as decisões judiciárias envolvem um universo social que vai além do que, na linguagem jurídica, é denominado valor da causa. Nesse sentido, as relações processuais não podem ser analisadas fora de todo o contexto social, haja vista que são regidas por relações humanas.

Dessa forma, a aplicação do Direito Sistêmico e a dinâmica da Constelação Familiar, surgem como alternativas na resolução de conflitos, na perspectiva de resolver problemas que vão além dos procedimentos processuais de causas jurídicas. O termo Constelação Familiar surgiu a partir de Anton Suitbert Hellinger, ou Bert Hellinger, na Alemanha, sob a nomenclatura de Familienaufstellen, que significa que cada membro familiar ocupe o lugar que lhe é destinado, como em uma constelação cósmica (Fernandes e Andrade, 2018).

Assim, a Constelação Familiar Sistêmica, por meio do Direito Sistêmico, assume cada vez mais importância como dinâmica de resolução de conflitos no âmbito do poder judiciário, influenciando uma prática de Justiça Restaurativa como uma ciência psicoterapêutica capaz de restaurar as vivências dos envolvidos, tanto da vítima como do agressor ou de qualquer indivíduo que tenha sido afetado pela incursão ao descumprimento da lei. Opondo-se à prática da Justiça Retributiva, onde a ênfase recai apenas sobre o crime como fator de violação da lei, incorrendo em pena com um fim em si mesmo, a Justiça Restaurativa se propõe a minimizar os agravos aos envolvidos e possibilitar a participação de todos na resolução dos conflitos e reparação dos danos causados, num processo de avaliação, entendimento e reeducação que considera as relações humanas e sociais que permearam os acontecimentos.

Sob essa perspectiva, esse artigo é resultado de uma pesquisa bibliográfica, com o objetivo de apresentar um breve histórico da prática do Direito Sistêmico no Brasil enquanto ferramenta na aplicação de uma dinâmica de Justiça Restaurativa, evidenciando sua importância no contexto jurídico brasileiro atual. O estudo é parte de uma pesquisa de mestrado em andamento 
que investiga a prática de 7 (sete) magistrados no Brasil acerca da prática do Direito Sistêmico. Além disso, as autoras vivenciam em seu cotidiano experiências com a prática das Constelações Familiares, atuando como voluntárias junto ao Poder Judiciário do Estado de Mato Grosso em oficinas de Direito Sistêmico para adolescentes em conflito com a lei.

\section{Metodologia}

No que se refere à metodologia de pesquisa aqui aplicada, utilizou-se a pesquisa bibliográfica numa perspectiva de natureza qualitativa, dada sua importância como suporte para fundamentar o conhecimento científico sobre a temática estudada. A pesquisa qualitativa nos permite analisar os acontecimentos sociais e suas influências nas relações que caracterizam os fatos, haja vista que, conforme Minayo (2009), algumas dimensões das relações humanas não se explicam pela quantificação. Em outras palavras, esse tipo de pesquisa possibilita a compreensão do mundo em que vivemos e o porquê de as coisas serem como são (Flick, 2009).

A importância da pesquisa bibliográfica, conforme destaca Gil (2008), "reside no fato de permitir ao investigador a cobertura de uma gama de fenômenos muito mais ampla do que aquela que poderia pesquisar diretamente" (p. 50). No caso desse estudo, é indispensável pelo fato de a investigação objetivar, principalmente, o estudo de fatos históricos a respeito do Direito Sistêmico como prática no judiciário brasileiro. Nesse caso, a pesquisa destaca, mais especificamente, a trajetória do magistrado Sami Storch como precursor da aplicação das Constelações Familiares e suas concepções acerca das possibilidades de conciliação na resolução de muitos conflitos judiciais, promovendo a prática do Direito Sistêmico como forma de solucionar mais produtivamente as questões que envolvem a lei e acelerar os processos, combatendo a sobrecarga e, consequentemente, a eventual morosidade no sistema jurídico brasileiro.

\section{Resultados e Discussão}

Em âmbito judicial, no Brasil, o método conciliatório se encontra em aplicação desde tempos remotos, sendo utilizado em causas cíveis e nas de menor complexidade, cujo rito está previsto na Lei n. 9.099/95, Lei dos Juizados Especiais, que também prevê aplicação aos crimes de menor potencial ofensivo, composição civil dos danos, como forma de resolver conflitos e evitar futura ação penal.

A partir da edição do novo Código Civil, em 2015, o sistema de conciliação nas questões judiciais passou a priorizar a resolução consensual entre as partes por meio da mediação jurídica. Nesse processo, metodologias alternativas passaram a ganhar prioridade no Sistema Judicial brasileiro como forma de solucionar antecipadamente os conflitos, conciliando acordos e evitando o prolongamento de ações penais. Além disso, em muitos casos, o sentenciamento judicial da questão coloca fim no processo, mas não evita que novas ocorrências venham a surgir no mesmo contexto, com os próprios envolvidos, haja vista que as motivações geradoras do conflito não foram detectadas e tampouco solucionadas.

Nessa perspectiva, o Direito Sistêmico e a Constelação Familiar surgem como possibilidades de respaldo a advogados e juízes na resolução de questões na área jurídica. Segundo o PROMAD ${ }^{1}$ (Programa Nacional de Modernização da Advocacia) uma das ferramentas de gestão mais utilizadas pelos advogados em todo o Brasil,

O Direito Sistêmico não é uma área independente do Direito. Trata-se de uma nova abordagem que analisa a aplicação das leis sistêmicas em todas as áreas do Direito. A proposta do Direito Sistêmico é justamente integrar a prática do Direito com a conciliação profunda envolvendo as partes. Compreendendo os fatores que transcendem as relações entre

\footnotetext{
${ }^{1}$ O PROMAD é uma plataforma que presta serviços jurídicos online aos advogados em parceria com a OAB, por meio de software e marketing jurídicos e criação de sites, tendo sido criada em 2008, durante a XX Conferência Nacional dos Advogados em Natal-RN.
} 
as partes, é possível buscar uma solução mais efetiva para os conflitos. ${ }^{2}$

Dessa forma, as práticas sistêmicas oferecem oportunidades de as partes discutirem em conjunto e não precisam necessariamente de que o magistrado faça pessoalmente as constelações ou oficinas, sendo esse trabalho delegado também aos advogados e/ou grupos de voluntários consteladores, havendo posteriormente o retorno das partes em juízo e a manifestação dos acordos pela extinção do processo ou da continuidade dos autos, caso o entendimento não ocorra.

\subsection{A aplicação da metodologia do Direito Sistêmico e da Constelação Familiar no Brasil}

No Brasil, o Direito Sistêmico foi preconizado por Sami Storch, magistrado pioneiro na aplicação da Constelação Familiar no Sistema Judiciário Brasileiro. Ele conheceu as constelações sistêmicas em 2004, quando era advogado. Hoje, magistrado jurisdicionando na comarca de Itabuna-BA, utiliza a referida técnica há mais de 12 anos, conquistando resultados na facilitação das constelações e na entrega da paz social aos jurisdicionados. "Ele (Storch) merece o reconhecimento de ser um pioneiro no campo do assim chamado Direito Sistêmico", conforme dito por Sophie Hellinger ${ }^{3}$.

Ao trazer o método para o exercício do Direito, Sami Storch entra para a Escola Hellinger Schulle na Alemanha e atualmente é referência no Brasil como criador do Direito Sistêmico, o qual representa a análise do Direito na visão das referidas ordens, que, segundo Hellinger (2020), regem as relações humanas. A aplicação de seus princípios pelos profissionais do Direito e das áreas afins, propõe encontrar a melhor solução para abranger o sistema envolvido no conflito. (Storch, 2010).

Ainda em 2012, Sami Storch, como Juiz de Direito em exercício na Bahia, começa a experimentar a inclusão dos princípios da Constelação Familiar na prática do Direito. Trata-se de um método terapêutico criado pelo ex padre alemão Bert Hellinger em 1978 e tem como princípio básico a resolução de conflitos por meio da inclusão de todas as partes envolvidas. Bert aprofundou-se na área terapêutica e percebe o mundo, em sua postura profissional, como a Abordagem Sistêmica Fenomenológica apresentando as Ordens do Amor: pertencimento, hierarquia e equilíbrio ${ }^{4}$ (Hellinger, 2020).

Vale ressaltar que Hellinger, criador do método, era pedagogo, teólogo, filósofo e psicanalista, formado também em análise transacional. $\mathrm{O}$ método pode ser considerado um procedimento terapêutico breve, denominado Constelação Familiar Sistêmica, e que tem sido incorporado em inúmeras práticas profissionais de terapeutas e psicoterapeutas no mundo todo, nas últimas três décadas, incluindo os profissionais da Psicologia. A Hellinger, é creditado o mérito de utilizar o campo de ressonância ${ }^{5}$ para desvelar as questões/problemas trazidos pelas pessoas, que consiste numa espécie de inconsciente coletivo que pode ser acessado mediante a autorização da pessoa demandante do temalquestão. Para ele todo autoconhecimento é necessário, inclusive desde tenra idade para que os padrões e as problemáticas dentro do sistema familiar, deixem de ser reprisados de forma inconsciente e cada um siga e esteja no seu caminho de cura pessoal de traumas transgeracionais, que hoje também é explicado pela herança epigenética ${ }^{6}$.

Storch, sendo adepto da filosofia de Hellinger, segundo Fernandes e Andrade (2018), iniciou com a adaptação de algumas práticas conciliatórias durante as audiências, permitindo que partes e advogados se expressassem, culminando posteriormente em

2https://www.promad.adv.br/blog/direito-sistemico/

${ }^{3}$ Storch, S. 2020. p. 13.

${ }^{4}$ Respectivamente: todos queremos pertencer ao nosso clã (mesmo que em lealdade a questões negativas); na família deve prevalecer a hierarquia de quem nasceu antes, no sentido de ocupar seus papéis (filhos que mandam nos pais etc.); equilíbrio entre o dar e receber, ou seja, equilíbrio entre as partes, algo que é trabalhado bastante nas questões conflituais do Direito.

${ }^{5}$ Campo morfogenético é um conceito referente a um campo hipotético que explicaria a emergência simultânea da mesma função adaptativa em populações biológicas não-contíguas. A hipótese dos campos morfogenéticos foi formulada por Rupert Sheldrake, biólogo contemporâneo inglês; existe uma troca, onde um consegue acessar o campo morfológico do outro, bem como nos campos das pessoas que estão participando da terapia (Sheldrake, 1996).

${ }^{6}$ Conceito que vem revolucionando a ideia de hereditariedade que se tinha até então, em que as vivências das gerações anteriores são passadas para a geração atual por meio de alterações na expressão do DNA - caso dos judeus que sofreram holocausto, da fome holandesa relatado no livro de Francis (2015) e, embora com poucas pesquisas, aplica-se por bom senso e extensão conceitual ao caso dos descendentes de escravizados no Brasil (Serafim, 2020). 
(...) palestras vivenciais, convidando as partes em litígio que tinham processo em sua vara para participar e com isso obteve excelentes resultados, pois antes das audiências de conciliação as pessoas experienciavam dinâmicas e vivências que as oportunizavam olhar para suas situações de um outro ângulo, e desta forma era alcançada a eficácia do processo judicial por meio de acordos [...] (p. 302).

De acordo com o Conselho Nacional de Justiça, em 2014, o Juiz Sami Storch conseguiu uma eficácia de $100 \%$ nos acordos durante as sessões de conciliação ${ }^{7}$. Essa metodologia na justiça brasileira, uma das primeiras mundialmente a utilizar a supracitada técnica alemã, está presente nas unidades de Justiça em ao menos dezesseis Estados e no Distrito Federal, sendo utilizada por meio do sistema Portas, na Teoria Geral dos Sistemas, Fenomenologia e Psicodrama, segundo dados do Conselho Nacional de justiça (CNJ, 2020). Sua importância e intenção jurídica é exatamente esclarecer às partes o que há por de trás do processo judicial, tendo como objetivo a pacificação social, quer seja em um único processo, quer em vários.

Todo esse processo encontra respaldo jurídico na resolução CNJ 125/2010, que tem como premissa incentivar a prática que favoreça o tratamento adequado aos conflitos. Ademais, o Código de Processo Civil apresenta medidas para suscitar a paz entre os atuais opostos, e dentre elas, está justamente a constelação familiar, criada por Bert Hellinger (CNJ, 2021). Tem-se assim, novas medidas alternativas de pacificação, oriundas dessa metodologia.

Como profissional do direito, Storch (2020) defende que todo operador do Direito está buscando uma reparação a uma ordem violada de seu sistema, ou precedência que foi invertida, um excluído, representando esta a vocação deste profissional. (Storch, 2020). Na magistratura, a percepção fica por conta das constelações que ajudam a olhar o processo como um todo, o que prioriza a visão e por conseguinte, melhora os resultados. Tais pontes servem para quem não consegue enxergar que as partes são um só, posto que a essência, o objetivo do processo judicial, dos institutos judiciais, é resolver conflitos, pacificar, unir, aproximar, somar.

Sob esse aspecto, um questionamento surge à tona quando se reflete sobre o papel do juiz ao utilizar-se dessa metodologia: este se deixaria influenciar pelas situações mostradas na constelação, havendo a possibilidade de parcialidade na aplicação da sentença? Nesse sentido, conforme Storch (2020), o juiz está no papel de decidir conforme a lei frente ao processo e quando tem uma visão ampla, sistêmica, de agente do Poder Judiciário, terá o posicionamento mais adequado e sua profissão deixa de ser um peso.

Importa considerar ainda que, em sentido sistêmico, quanto menos dados técnicos e cumpríveis a sentença tiver, maior será a probabilidade de haver outra sentença num novo processo. Isso ocorre quando um processo finaliza com uma sentença e se faz necessária a execução desta decisão judicial, sendo certo que, ao final desta execução, a qual tornou-se novo processo, haverá mais uma sentença. Tal fato representa maior carga de processos para a justiça, implicando também em inexistência de aplicação do Direito Sistêmico anteriormente (Storch, 2020). Consequentemente, a constelação ajuda o magistrado a ter uma visão clara, ampla, chegando a um julgamento justo e pacífico. E é exatamente essa evolução, buscando decisões com maior poder de ajuda, aplicando as ordens do amor/ajuda de Hellinger, que fazem a diferença.

Desenvolver tal visão apurada de constelador, faz com o juiz adapte ao seu trabalho diário e finalize os processos de forma a buscar a paz social, presença sumária do Direito Sistêmico. Nessa perspectiva, Storch defende que o uso das técnicas de Constelações Familiares no âmbito do Judiciário brasileiro, frente à solução de conflitos judiciais, constitui-se uma visão sistêmica do direito, pela qual só há direito quando a solução traz paz e equilíbrio para todo o sistema. Depois de todo seu estudo, uma observação salutar foi apresentada e continua sendo constatada por Storch e todos que o seguiram: as constelações familiares representam uma das melhores práticas para o encontro entre ofensor e ofendido, restaurando a dignidade dos envolvidos (Storch, 2020).

7 Notícia publicada pelo CNJ em 17/11/2014 em https://www.cnj.jus.br/juiz-consegue-100-de-acordos-usando-tecnica-alema-antes-dassessoes-de-conciliacao. 
No Estado de Mato Grosso, conforme Arruda Junior ${ }^{8}$ (2017), podem ser citados como referências na aplicação do Direito Sistêmico e Constelações Familiares no Judiciário Mato-grossense a Dra. Jaqueline Cherulli, Juíza da $3^{\text {a }}$ Vara de Família e Sucessões de Várzea Grande, e o Juiz da Vara de Violência Doméstica da Capital, Dr. Jamilsom Haddad. Segundo o advogado, ambos vêm obtendo grandes êxitos nos acordos Judiciais. Em sua concepção, a prática das Constelações "ajuda os participantes a romperem com o ciclo de repetição, superando o trauma, e conduzindo as partes a um reconhecimento mútuo e um efetivo respeito entre si, favorecendo a conciliação e evitando futuros litígios". ${ }^{9}$

\subsection{O Direito Sistêmico e sua influência na Justiça Restaurativa}

Quando se fala em meio jurídico e comunitário, surge ainda uma nova possibilidade de resolução de conflitos, representando uma alternativa para a real experiência de justiça, a qual será experimentada pelas partes: a Justiça Restaurativa.

No Brasil, ela tem sido disseminada como conceito, filosofia e prática, e teve origem durante as décadas de 1970 e 1980 nos Estados Unidos e Canadá. Tais experiências iniciais deram vida a outras e a partir da década de 1980 a Justiça Restaurativa se fundamenta no âmbito da criminologia, estabelecendo-se a partir de críticas ao sistema penal e na problematização do papel da vítima, o qual foi relegado ao silenciamento em função da autoridade conferida pelo Estado (Leite, 2017). A Organização das Nações Unidas - ONU - com o intuito de regulamentar as práticas de Justiça Restaurativa no mundo, emitiu três resoluções nos anos de 1999 a 2002: 1999/26, 2000/14 e 2002/12. Esses documentos servem de referências para o trabalho da Justiça Restaurativa nos países signatários da ONU (1999).

No Brasil, a Justiça Restaurativa tem seu marco legal com a Carta de Brasília, a qual manteve as características contidas na Resolução 2002/12, supracitada. Esse último documento "Encoraja os Estados Membros a inspirar-se nos princípios básicos para programas de justiça restaurativa em matéria criminal no desenvolvimento e implementação de programas de justiça restaurativa na área criminal" (ECOSOC, 2002 p. 02), conforme segue:

1. Programa de Justiça Restaurativa significa qualquer programa que use processos restaurativos e objetive atingir resultados restaurativos.

2. Processo restaurativo significa qualquer processo no qual a vítima e o ofensor, e, quando apropriado, quaisquer outros indivíduos ou membros da comunidade afetados por um crime, participam ativamente na resolução das questões oriundas do crime, geralmente com a ajuda de um facilitador.

3. Resultado restaurativo significa um acordo construído no processo restaurativo que inclui respostas e programas, tais como reparação, restituição e serviço comunitário, objetivando atender as necessidades individuais e coletivas e responsabilidades das partes, bem como promover a reintegração da vítima e do ofensor. Partes significativas são a vítima, o ofensor e quaisquer outros indivíduos ou membros da comunidade afetados por um crime, que podem ser envolvidos em um processo restaurativo. Facilitador é aquele cujo papel é facilitar, de maneira justa e imparcial, a participação das pessoas afetadas e envolvidas num processo restaurativo (trecho da Resolução 2002/12 da ONU).

Segundo o Conselho Econômico e Social da ONU, por meio da já referida resolução 2002/12, este processo restaurativo representa qualquer processo em que a vítima e o ofensor, ou mesmo qualquer outro sujeito da comunidade que tenha sido afetado pelo crime, participe ativamente na resolução das questões oriundas deste crime, o que ocorre geralmente com a ajuda de um facilitador. Nesse sentido, a Justiça Restaurativa se opõe à Justiça Retributiva, uma vez que na perspectiva dessa última o crime é definido pela violação da lei, enquanto pela visão restaurativa o crime é definido pelo dano à pessoa e ao relacionamento (Zehr, 2008; Iipr, 2020); e justamente por isto ela se propõe restaurar a vida das pessoas, de forma pacífica e independentemente de que lado elas estão referindo-nos aos papéis de vítima e agressor.

\footnotetext{
${ }^{8}$ Anselmo Falcão de Arruda Júnior é advogado sistêmico, mediador e conciliador membro da Comissão Especial Conciliação, Mediação e Arbitragem da OAB-MT.

${ }^{9}$ https://www.oabmt.org.br/artigo/350/o-direito-sistemico.
} 
O que a Justiça Restaurativa propõe é ampliar o círculo de participação na resolução da controvérsia, com pessoas direta ou indiretamente afetadas e que podem contribuir para a solução por integrar a rede de confiança ou a rede social relacionada ao contexto do caso em análise (Leite, 2017).

Assim, ela representa a resposta à dignidade e igualdade das pessoas; constrói o entendimento e promove harmonia social frente a restauração das vítimas, ofensores e comunidades. É uma abordagem que permite que as pessoas afetadas por crimes, compartilhem seus sentimentos e experiências, e/ou desejos que atendam suas necessidades. Quanto aos ofensores, autoriza-os a compreenderem as causas e consequências do seu comportamento e ainda, de assumir a responsabilidade de forma efetiva. Para a comunidade, a compreensão das causas adjacentes do crime, para compreensão do bem-estar comunitário e prevenção da criminalidade fica evidenciada (Grecco, 2014).

Quando a Justiça é vista em Círculo ${ }^{10}$, conforme Grecco (2014), representada por uma equipe multidisciplinar de capacitadores da Justiça Restaurativa, e vivencia encontros e projetos de trabalho, os princípios, valores e força deste Círculo, que são o respeito pelo outro, a colaboração, a conexão às necessidades de uma e outra pessoa, não perdendo aquele sentido da coletividade, ficam muito apurados. Segundo o mesmo autor, Kay Pranis ${ }^{11}$ representa um exemplo deste círculo, trazendo nuances e situações diferentes, como os formatos conversacionais e as metodologias restaurativas, apresentando-os de forma prática e gerando assim, mais praticidade para trabalhar com a comunidade envolvida.

Segundo Pranis (2010) o objetivo é corrigir as situações de dano existente entre as pessoas que não estão conectadas com a vida, em relação àquelas que estão conectadas, e para ajudar é necessário encontrar um caminho de cicatrização e cura. O povo Navajo ${ }^{12}$ tomava diversas medidas quando algumas pessoas causavam danos às outras, e assim agindo visualizavam a melhora e aprofundavam-se em sua comunidade, buscando melhorar a forma de viver, corrigindo as situações, ajudando a reconectá-los com a comunidade onde vivem, e conectar-se com sua própria comunidade pela primeira vez.

Tais processos contribuem para que os responsáveis pelos danos causados, trabalhem seus pensamentos confusos, à primeira vez, reconhecendo o prejuízo causado a comunidade e aquela pessoa que foi afetada, buscando formas de reparar, inclusive seus ancestrais. Dita nesta denominação, ela projeta-se como proposta de promover, entre os verdadeiros protagonistas dos conflitos, inúmeras iniciativas de solidariedade, diálogo, forma consensual e plano de ação reconciliador. De forma ampla, qualquer ação que objetive fazer justiça por meio da reparação do dano causado pode ser considerada como esta prática.

Os movimentos, como a Justiça Restaurativa, que visam promover a sociedade/comunidade e recuperar tradições comuns em geral, em virtude do modelo social cujas práticas de regulamento social encontram-se centradas na manutenção da maior coesão grupal possível, tem interesses que superam os individuais e a transgressão de uma norma causava reações orientadas para o restabelecimento do equilíbrio rompido (Greco 2014). Pranis (2021) quando proferiu uma palestra com o tema: "A filosofia da Justiça Restaurativa e os processos restaurativos” recorda que os processos vêm para lembrar quem nós realmente

\footnotetext{
${ }^{10}$ Os chamados círculos restaurativos são outra ferramenta dentro da Justiça Restaurativa e são usados para mediação/resolução de conflitos, inclusive também em empresas e escolas; bem como de aprendizagem em espaços de formação. "O Círculo Restaurativo ou Círculo de Construção de Paz mobiliza em nós o princípio da interconectividade enquanto fenômeno ontológico e social que nos guia dentro do Círculo no exato momento de seu acontecer, mas, que também nos guia fora dele, pois ao se constituir em experiência vivida, pode, quando conduzido pela reflexão crítica, tornar-se dispositivo para a mudança de nossos padrões de comportamento, reafirmando o nosso pertencimento à espécie humana." (Fernandes e Hir, 2020)

11 Kay Pranis é uma pessoa fundamental para a disseminação dos círculos; consultora da ONU para a Justiça Restaurativa, viveu entre os Navajos, grupo indígena norte americano (rodapé 7) com a qual aprendeu e vivenciou os princípios da circularidade para resolução de conflitos. 12 Os navajos (em navajo: Diné ou Nabeehó) são um povo indígena da América do Norte, da família linguística Athapaskan (idioma navajo) e da área cultural Sudoeste. Originalmente, imigraram das áreas do norte e durante o século XVI tornaram-se um povo pastor e caçador. O povo vive numa reserva no nordeste do Arizona e continua em partes do Novo México e Utah. É uma enorme área que vai desde Grants no Novo México, até o Grand Canyon, no Arizona; de Holbrook, no centro do Arizona até o Rio San Juan, já no Colorado, inclui Monument Valley, parte do Deserto Pintado e parte da Floresta Petrificada. De acordo com o censo dos Estados Unidos de 1990, o total de índios navajos era de 220.000, vivendo em 6 milhões de hectares, com um produto interno bruto estimado em 50 milhões de dólares. Disponível em Navajos - Wikipédia, a enciclopédia livre (wikipedia.org)
} 
somos.

Assim, o Direito Sistêmico é, portanto, uma estratégialferramenta que coaduna com a Justiça Restaurativa. Storch (2021) argumenta que, aqueles que foram excluídos pela família, são vistos e sentidos, reconhecidos e devolvidos aos seus lugares sem quaisquer tipos de julgamento. A mesma situação acontece quando alguém foi adotado e não sabe sua origem biológica. É necessário que pais, professores e sociedade vejam as crianças com toda sua realidade; sem negá-la. Desta forma, o Direito Sistêmico e a Justiça Restaurativa são utilizados no princípio da Dignidade da Pessoa Humana, e o magistrado não deveria ter prioridade sobre a decisão familiar, determinando acordos que poderiam ser melhor aceitos e resolvidos com o entendimento entre as partes. A conexão, a força está presente na Justiça Restaurativa, principalmente, e tudo muda quando ela é efetivamente aplicada. (Storch, 2021).

Para um modelo restaurativo, serão utilizadas as pessoas envolvidas no caso, seus verdadeiros protagonistas, e o Estado, por meio de seus operadores, promoverá unicamente no âmbito adequado para que as pessoas possam elaborar, dialogar e transformar suas controvérsias, conflitos e relações, garantindo os direitos constitucionais de todos os envolvidos, a considerar também os interesses coletivos (Leite, 2017).

São indicadores da Justiça Restaurativa, conforme propõe Leite (2017), apud Harry Mika e Howard Zehr:

1. Foco nos danos causados pelo crime ao invés de nas leis que foram infringidas;

2. Ter igual preocupação e compromisso com vítimas e ofensores, envolvendo a ambos no processo de fazer justiça;

3. Trabalhar pela recuperação das vítimas, empoderando-as e atendendo às necessidades que elas manifestam;

4. Apoiar os ofensores e ao mesmo tempo encorajá-los a compreender, aceitar e cumprir suas obrigações;

5. Reconhecer que, embora difíceis, as obrigações do ofensor não devem ser impostas como castigo, e precisam ser exequíveis;

6. Oferecer oportunidades de diálogo, direto ou indireto, entre vítima e ofensor, conforme parecer adequado à situação;

7. Encontrar um modo significativo para envolver a comunidade e tratar as causas comunitárias do crime;

8. Estimular a colaboração e reintegração de vítimas e ofensores, ao invés de impor coerção e isolamento;

9. Dar atenção às consequências não intencionais e indesejadas das ações e programas de Justiça Restaurativa;

10. Mostrar respeito por todas as partes envolvidas: vítimas, ofensores e colegas da área jurídica.

Para o Conselho Nacional de Justiça, a Justiça Restaurativa é incentivada por meio de um Protocolo de Cooperação para a difusão daquele firmado em agosto de 2014 com a Associação dos Magistrados Brasileiros (AMB), e trata de prática que busca conceito, sendo processo colaborativo que procura a resolução de conflito caracterizado como crime, o qual envolve a participação maior do infrator e da vítima. A mediação vítima-ofensor significa colocá-los no mesmo ambiente guardado de segurança jurídica e física, objetivando a resolução do problema. Não há somente punição, mas também reparação de danos emocionais.

Quem realiza a Justiça Restaurativa é um mediador, o qual faz o encontro entre a vítima e o ofensor e alguém que apoie este, o que não significa apoiar o crime e sim, um plano de reparação de danos.

Fica bem claro para o Conselho Nacional de Justiça, que a Justiça Restaurativa pode ser aplicada em crimes considerados mais leves e nos mais graves, mas é necessário ter estrutura física e de pessoal para o acontecimento. Ademais, são concomitantes, a Justiça Restaurativa e a pena tradicional, isto porque o mediador não estabelece sentença penal ou redução, ele limita-se a propor acordos de reparação de danos (CNJ, 2017).

É suplementar a intervenção da Justiça Restaurativa com o processo, sendo oferecido um ambiente para solução de problemas jurídicos relacionados ao conflito, onde se busca a persuasão, após a dissuasão e então mecanismos de interdição (internação), p.ex. no caso de adolescentes. Nesse sentido, o maior benefício da Justiça Restaurativa é alcançar a pacificação das relações sociais de forma um tanto mais efetiva e menos judicial (CNJ, 2017). 


\section{Considerações Finais}

O objetivo proposto com a pesquisa foi atingido mediante a apresentação do breve percurso histórico da prática das Constelações Familiares e do Direito Sistêmico preconizados por Sami Storch enquanto disseminador das ideias de Bert Hellinger, considerando os fatores humanos e os contextos sociais nas relações entre o Sistema Jurídico e comunidade em geral.

Os resultados obtidos convergem para a constatação de que a metodologia de Constelações Familiares no Sistema Judicial brasileiro em muito tem contribuído para a resolução dos conflitos de forma mais efetiva, colaborativa e humanitária. Pode-se concluir, a partir desse estudo, que os princípios do Direito Sistêmico se constituem como prática da Justiça Restaurativa, sendo estas duas abordagens importantes bem como as mediações, os círculos restaurativos, e outras práticas/ferramentas consideradas de restauração e reparação, sobretudo dos danos emocionais, buscando o que nas constelações familiares chamase de equilíbrio entre o dar e o receber; princípio basilar das relações humanas, convergindo na concretização de um Sistema Judicial mais efetivo e dinâmico.

Vale ressaltar que em âmbito de pesquisa científica, o estudo gerou, em nível de uma formação para o mestrado ainda em andamento, resultados que possibilitam o vislumbre de uma comunidade acadêmica futuramente melhor preparada para a resolução de conflitos, cada um olhando para sua história e integrando a Universidade dentro desses contextos, a partir de disciplinas que possibilitem a prática do novo paradigma da Justiça Restaurativa aqui apresentado, principalmente na formação do bacharel em Direito.

Ainda estamos longe de uma implantação generalizada, como todo novo paradigma, pois abordar o Direito Sistêmico compete aplicar a prática da ciência jurídica frente a este viés terapêutico, iniciando com a elaboração de leis, após aplicação aos casos concretos, onde se vislumbra utilizá-las para tratar questões geradoras de conflitos e encontrar as soluções adequadas no contexto geral.

\section{Referências}

Arruda Junior. A. F. de (2017). O Direito Sistêmico. https://www.oabmt.org.br/artigo/350/o-direito-sistemico.

Brasil. (2017). Base Nacional Comum Curricular (BNCC). Educação é a Base. Brasília: MEC http://basenacionalcomum.mec.gov. br/images/BNCC_20dez_site.pdf.

Brasil. (2020). Conselho Nacional de Justiça (CNJ). Brasília, disponível em Justiça Restaurativa: o que é e como funciona - Portal CNJ.

Brasil. (2015) Lei no 13.105, de 16 de março de 2015. Código de Processo Civil. Diário Oficial da União, Brasília, DF, 17 mar: http://www.planalto.gov.br/ccivil_03/_Ato2015-2018/2015/Lei/L13105.htm.

Brasil. (2021). Ministério da Justiça e Segurança Pública. Brasília. www.gov.br.

Ecosoc. (2002) Conselho Social e Econômico. Resolução 2002/12 da ONU - Princípios básicos para utilização de Programas de Justiça Restaurativa em Matéria Criminal.

Fernandes E. C. G. \& Andrade. Y. M. M de (2018). O início da aplicação do Direito Sistêmico. Anais do Congresso Catarinense de Direito Processual Civil. 298-310. www.univali.br/eventos.

Fernandes, C. T.; \& Hir, J.C.A. (2020). Círculos da Paz e Freireanos: Conexões emergentes. Revista Educação, Psicologia e Interfaces. 4 (4).

Flick, U. (2009). Introdução à pesquisa qualitativa. (3a ed.), Artmed.

Gil, A. C. (2008) Métodos e técnicas de pesquisa social / Antonio Carlos Gil. (6a ed.), Atlas.

Grecco, A. et al. (2014). Justiça Restaurativa em Ação. Práticas e Reflexões. Dasheditora.

Hellinger B. (2006). A simetria oculta do amor: porque o amor faz os relacionamentos darem certo. Revisão técnica de Esther Frankel, Milton Corrêa e Mimansa Farny. (6a ed.), Cultrix.

Hellinger, B. (2019). Meu trabalho, minha vida: a autobiografia do criador da Constelação Familiar. Editora Pensamento-Cultrix.

IIPR - Instituto Internacional de Práticas Restaurativas (2020) - Definindo o termo "restaurativo" de Ted Wachtel, Presidente e Fundador do IIRP. https://www.iirp.edu/pdf/Defining-Restorative-Portuguese.pdf. Acesso em: 13 novembro de 2020. 
Research, Society and Development, v. 10, n. 13, e328101320527, 2021

(CC BY 4.0) | ISSN 2525-3409 | DOI: http://dx.doi.org/10.33448/rsd-v10i13.20527

Leite, F. (2017). Manual de Gestão para Alternativas Penais: Práticas de Justiça Restaurativa. Governo do Brasil. Ministério da Justiça e Cidadania.

Minayo, M. C. S. (2009). (Org.) Pesquisa Social. Teoria, método e criatividade. (28a ed.), Vozes.

ONU (1999) Organização das Nações Unidas. Declaração sobre uma Cultura de Paz. 107ª sessão plenária 13 de setembro.

Possato A. Constelação Sistêmica: Tudo sobre Constelação Familiar Sistêmica e Constelação Estrutural. Blog. https://constelacaosistemica.wordpress.com/.

Pranis, K. (2010). Processos circulares de construção de paz. (Tradução: Tônia Van Acker) Palas Athena.

Pranis, K. (2021). Aula 08. Pressupostos dos Círculos de Construção de Paz. [AULA 8] Os Pressupostos dos Círculos de Construção de Paz - YouTube.

Sheldrake, R. (1996). A Presença do Passado: Ressonância Mórfica, Instituto Piaget.

Storch, S. (2021) Aula 09. Olhar Sistêmico nas Práticas Restaurativas. [AULA 9] Olhar Sistêmico nas Práticas Restaurativas - YouTube.

Storch, S. (2021). Direito Sistêmico. Home - Direito Sistêmico (direitosistemico.com.br).

Zehr, H. (2008). Trocando as lentes: Justiça Restaurativa para o nosso tempo. (Tradução: Tônia Van Acker). Palas Athena. 